\title{
AURICULAR SEPTAL DEFECT IN ONE OF MONOZYGOTIC TWINS
}

\author{
BY \\ CONSTANCE C. FORSYTH and IRENE UCHIDA \\ From the Departments of Paediatrics and Zoology, University of Toronto, Canada
}

(Rrceived for Publication February 15, 1951)

In the cardiac clinic of the Hospital for Sick Children, Toronto, a 6-year-old girl with an auricular septal defect was found to have a monozygotic twin in whom the heart was normal.

Instances of congenital heart disease in both of monozygotic twins have been reported by several authors. Smith (1929) observed a patent ductus arteriosus in both of twin boys of similar general appearance, size, and weight. Ullrich (1938) described a case of congenital hypertrophy of the heart muscle in two members of a set of triplets that developed from two ova. The monozygotic pair were the affected ones, the third member being normal. Cor biloculare and persistent truncus arteriosus in both of twin brothers was found by Giustra and Tosti (1939). Pezzi and Carugati's cases (1924) of concordant dextrocardia with situs inversus in twin soldiers have been quoted by various authors as an instance of congenital heart disease in monozygotic twins, but the original article makes no reference to the zygosity of the twins.

On the other hand, congenital cardiac abnormalities in one member of a monozygotic twin pair have also been reported. Dubreuil-Chambardel (1927) observed monozygotic twins in France, only one of whom had dextrocardia and transposition of the viscera. In Germany Weitz (1936) noted patent ductus arteriosus also occurring in only one of a monozygotic pair. Rabl and Schulz (1940) erroneously report Dissmann's (1932) description of congenital aortic stenosis as appearing in one of uniovular twins. The original paper, however, describes these children as binovular twins. In the English literature we have been able to locate one case of discordance. A patent ductus arteriosus in one of twin girls is described by McClintock (1945). In her article there is an interesting history of identical twins on both the maternal and paternal sides of the family. However, the only evidence of monozygosity mentioned in her paper is that of a single placenta which is now known to be insufficient proof. To these instances of congenital heart disease

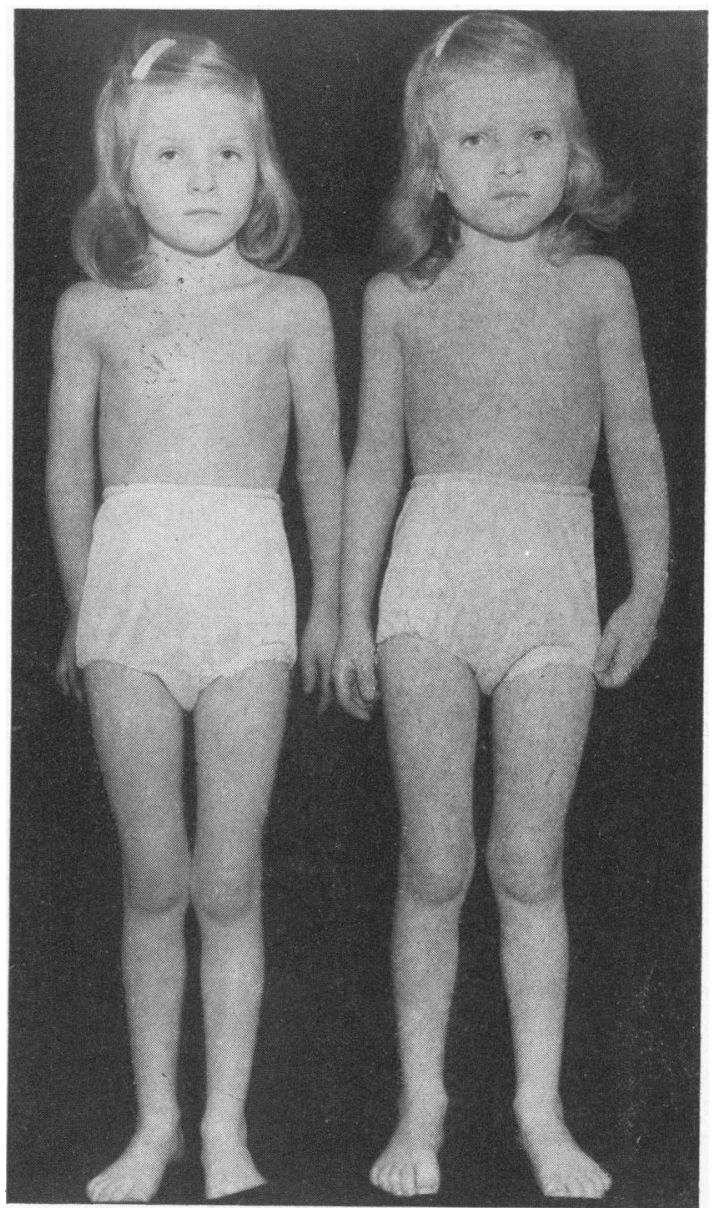

Fig. 1.-The twins (Deanna on the left and Donna on the right). 
in one of identical twins, we should like to add the present report.

\section{Case Report}

The twins, Donna and Deanna, were born in Toronto on November 30,1943, the only children of a mother aged 19 years at the time of delivery. There is no known family history of twinning on either side, nor of congenital defects. Both parents' blood tests were negative for syphilis. The mother was well during her pregnancy and did not suffer from any disease, such as German measles. child is every bit as active as her twin. Both children have had chickenpox and measles. Deanna had infective hepatitis in 1949, at which time she was seen at the Hospital for Sick Children and the congenital heart lesion was first diagnosed.

Evidence of Monozygosity. In physical appearance, the children are extremely alike, as may be seen from the accompanying photograph (Fig. 1). The affected twin (Deanna) is slightly smaller and lighter than her sister, being $44 \frac{1}{2}$ in. tall and $38 \frac{1}{2} \mathrm{lb}$. in weight, compared with Donna's height of $45 \frac{1}{4}$ in. and weight of $40 \mathrm{lb}$. Both

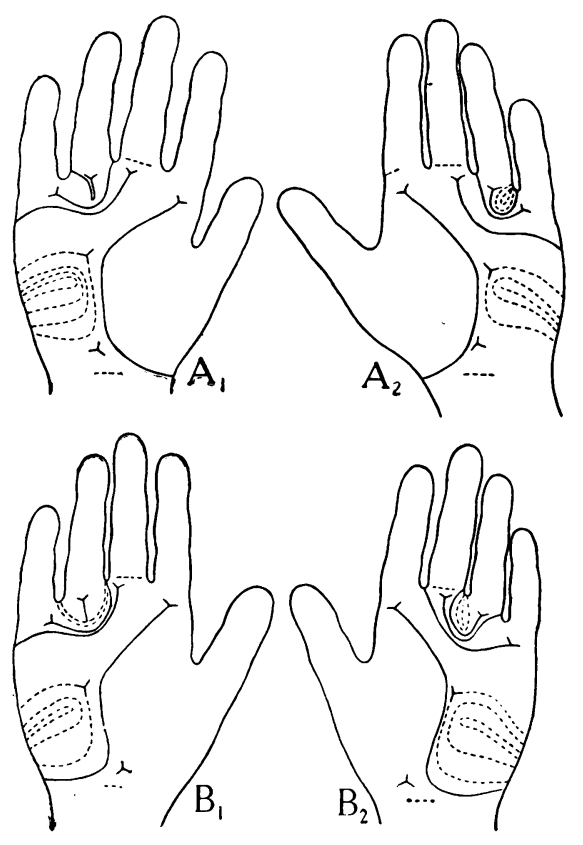

FIG. 2."-Prints of palms and soles of (A) Donna and (B) Deanna.

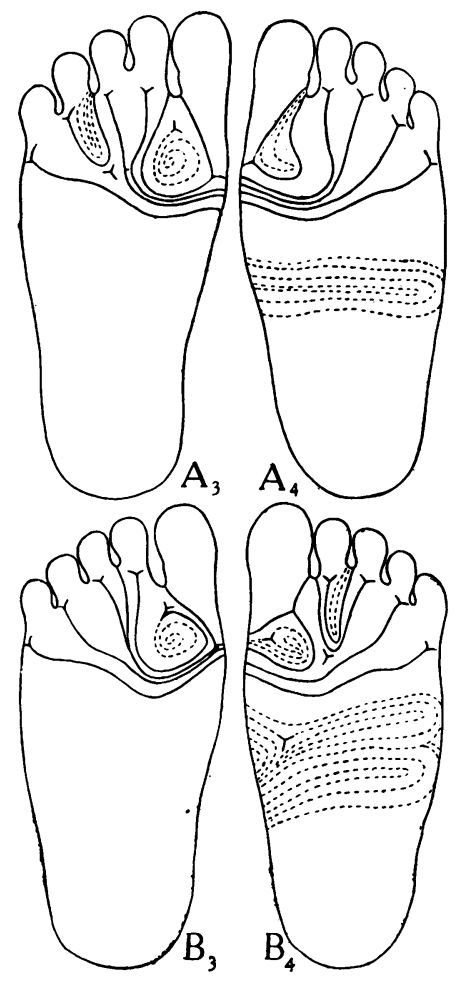

have a fair complexion, blonde hair, and blue eyes. The ears are very similar, and the teeth are alike in shape and occlusion. They show wide diastemata between the upper lateral incisors and cuspids. The children are both right-handed, and have in common a quiet, shy disposition. They are of normal intelligence.

The dermal configurations, which were printed by the Faurot technique and formulated according to standard methods (Cummins and Midlo, 1943), revealed similarities of the type found in monozygotic twins. The accompanying diagrams (Fig. 2) and formulations (Table 1) of the palms and soles illustrate the resemblances between Donna and Deanna. The homologous hands and feet of the twins are more nearly alike than the two hands or two feet of either one individual. twin being about a month ahead of her sister. A present both children are attending school. The affected 
TABLE 1

Digital, Palmar, and Plantar formulae of the Twins

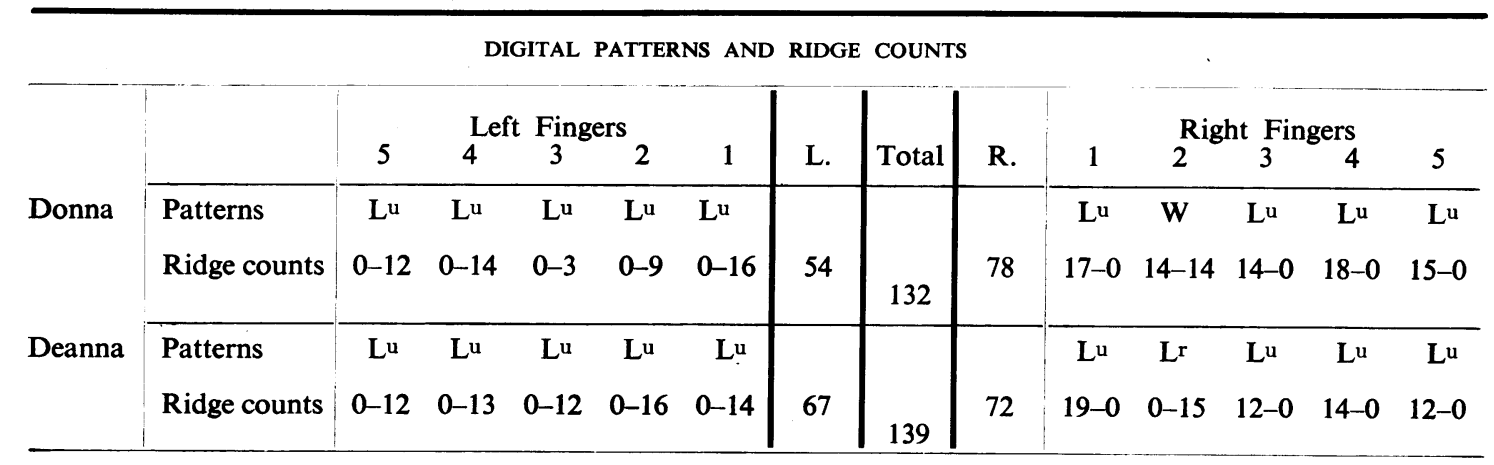

PALMAR FORMULAE

\begin{tabular}{|c|c|c|c|c|c|c|c|}
\hline & \multicolumn{3}{|c|}{ Left Palm } & \multicolumn{4}{|c|}{ Right Palm } \\
\hline & Main Lines & $\underset{\text { Triradii }}{\text { Axial }}$ & Patterns & Main Lines & & $\underset{\text { Triradii }}{\text { Axial }}$ & Patterns \\
\hline Donna & $\begin{array}{llll}9 & .7(X) . & 5^{\prime \prime} & .1\end{array}$ & $\mathrm{tt}^{\prime \prime}$ & $\mathrm{L}^{\mathrm{u} .0 .0 .0 .1(0)}$ & $9(8) . \quad 7(6) . \quad 5^{\prime \prime}$ & .1 & $\mathrm{tt}^{\prime \prime}$ & $\mathrm{L}^{u} \cdot \mathbf{0 . 0 . 0 . L}$ \\
\hline Deanna & $9(10) . \quad \times \quad .5^{\prime \prime}(6) \quad .3$ & $\mathrm{tt}^{\prime \prime}$ & $L^{u} \cdot 0.0 .0 . \quad 0$ & $11 \quad .9(10) .7(8)$ & .3 & $\mathrm{tt}^{\prime \prime}$ & $\mathrm{Lu}^{\mathrm{u}}$.0.0.L.0 \\
\hline
\end{tabular}

PLANTAR FORMULAE

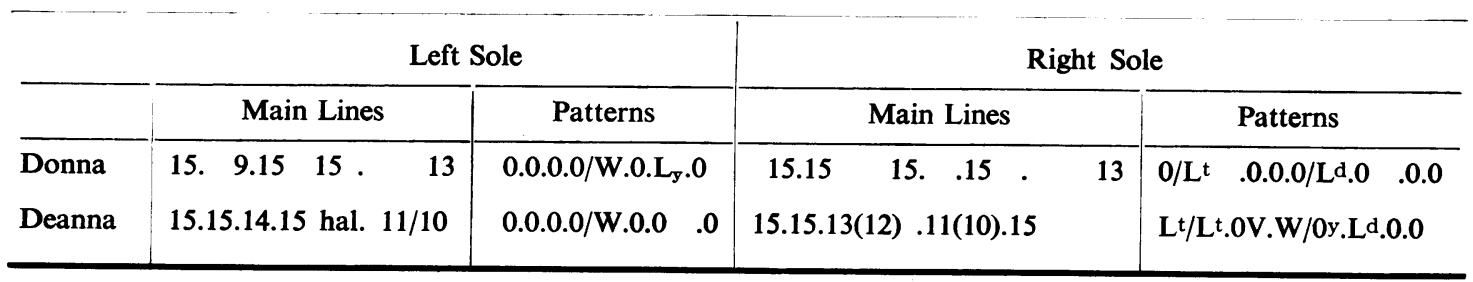

Symbols: Lu, loop ulnar; Lr, loop radial; W, whorl; X, abortive main line; $t$, axial triradius; La, loop distal; Lt, loop tibial; V, vestige of pattern; $y$, proximal triradius; hal, hallucal pattern.

TABLE 2

Percentage Difference Between Hands of Twins Compared with Averages for Monozygotic and Dizygotic TwINS

\begin{tabular}{|c|c|c|c|c|c|}
\hline & $\begin{array}{c}\text { Ridge Counts } \\
\text { of Fingers } \\
(\%)\end{array}$ & $\begin{array}{c}\text { Types of Finger } \\
\text { Patterns } \\
(\%)\end{array}$ & $\begin{array}{c}\text { Main Lines and } \\
\text { Axial Triradii } \\
(\%)\end{array}$ & $\begin{array}{l}\text { Palmar } \\
\text { Patterns } \\
\quad(\%)\end{array}$ & $\begin{array}{c}\text { Average } \\
\text { Difference } \\
(\%)\end{array}$ \\
\hline $\begin{array}{l}\text { Donna and Deanna } \\
\text { Monozygotic* twins } \\
\text { Dizygotic twins }\end{array}$ & $\begin{array}{l}15 \cdot 2 \\
10 \cdot 9 \\
32 \cdot 5\end{array}$ & $\begin{array}{l}10 \cdot 0 \\
23 \cdot 0 \\
47 \cdot 0\end{array}$ & $\begin{array}{l}28 \cdot 4 \\
17 \cdot 6 \\
31 \cdot 5\end{array}$ & $\begin{array}{l}25 \cdot 0 \\
21 \cdot 4 \\
32 \cdot 0\end{array}$ & $\begin{array}{l}19 \cdot 7 \\
15 \cdot 9 \\
34 \cdot 0\end{array}$ \\
\hline
\end{tabular}

* Percentage differences for monozygotic and dizygotic twins are from unpublished data of Ford Walker. 
Analysis of the digital and palmar configurations shows that the total difference of $19.7 \%$ between the pair follows the mean difference for monozygotic rather than for dizygotic twins (Table 2). The plantar formulae show slightly more variability (Table 3 ). The blood group

TABLE 3

Percentage Difference Between Soles of Twins COMPARED WITH AVERAGES FOR MONOZYGOTIC AND DIZYGOTIC TWINS

\begin{tabular}{ll|c|c}
\hline & & $\begin{array}{c}\text { Main } \\
\text { Lines (\%) }\end{array}$ & $\begin{array}{c}\text { Plantar } \\
\text { Patterns (\%) }\end{array}$ \\
\hline \begin{tabular}{ll|c} 
Donna and Deanna \\
Monozygotic twins
\end{tabular} & $\ldots$ & $45 \cdot 0$ & $28 \cdot 6$ \\
Dizygotic twins .. &.. & $66 \cdot 1$ & $32 \cdot 7$ \\
\hline
\end{tabular}

studies are summarized in Table 4 and show complete concordance. All the evidence taken together, therefore, shows that Donna and Deanna are monozygotic twins.

TABLE 4

Blood Groupings of Twins and their Parents

\begin{tabular}{|c|c|c|c|}
\hline & Group & $\begin{array}{l}\mathbf{M} \text { and } \mathbf{N} \\
\text { Grouping }\end{array}$ & Rh Grouping \\
\hline $\begin{array}{l}\text { Donna } \\
\text { Deanna } \\
\text { Father } \\
\text { Mother }\end{array}$ & $\begin{array}{l}\mathbf{A}_{1} \\
\mathbf{A}_{1} \\
\mathbf{A}_{1} \\
\mathbf{O}\end{array}$ & $\begin{array}{l}\mathbf{N} \\
\mathbf{N} \\
\mathbf{M N} \\
\mathbf{M N}\end{array}$ & $\begin{array}{l}\text { Negative cde/cde } \\
\text { Negative cde/cde } \\
\text { Positive cDE } \\
\text { Negative cde/cde }\end{array}$ \\
\hline
\end{tabular}

The Heart Lesion. Deanna has an auricular septal defect. There is no cyanosis or clubbing of the fingers. The femoral arteries are palpable and the blood pressure $110 / 60 \mathrm{~mm}$. Hg. The apex beat is in the fifth space inside the mid-clavicular line. On palpation, the heart beat is forceful, but no thrill is detectable. There is a moderately loud, blowing, systolic murmur of moderate duration heard maximally in the pulmonary area, but detected also all over the praecordium and posteriorly between the scapulae. There is an accentuated second pulmonary sound. Fluoroscopic examination reveals moderate cardiac enlargement, the ratio of the transverse diameter of the heart to the internal diameter of the chest being $10.0 \mathrm{~cm} .: 18.5 \mathrm{~cm}$. The enlargement affects both ventricles and, in addition, there is bulging of the pulmonary conus. The hilar shadows are of increased density and are actively pulsatile. The radiograph is reproduced in Fig. 3 together with that of Donna. Right axis deviation is seen only in Deanna's electrocardiogram (Fig. 4), her sister's being normal. The results of cardiac catheterization for the affected child are seen in Table 5. The rise of oxygen content in the right auricle is significant, and anatomical proof of auricular septal defect was furnished by the entry of the tip of the catheter into the left auricle and then into a pulmonary vein. The pressure readings in the various chambers were within normal limits.
TABLE 5

Results of Cardiac Catheterization of Deanna

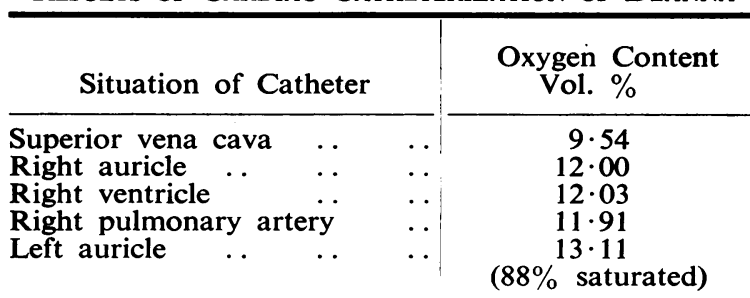
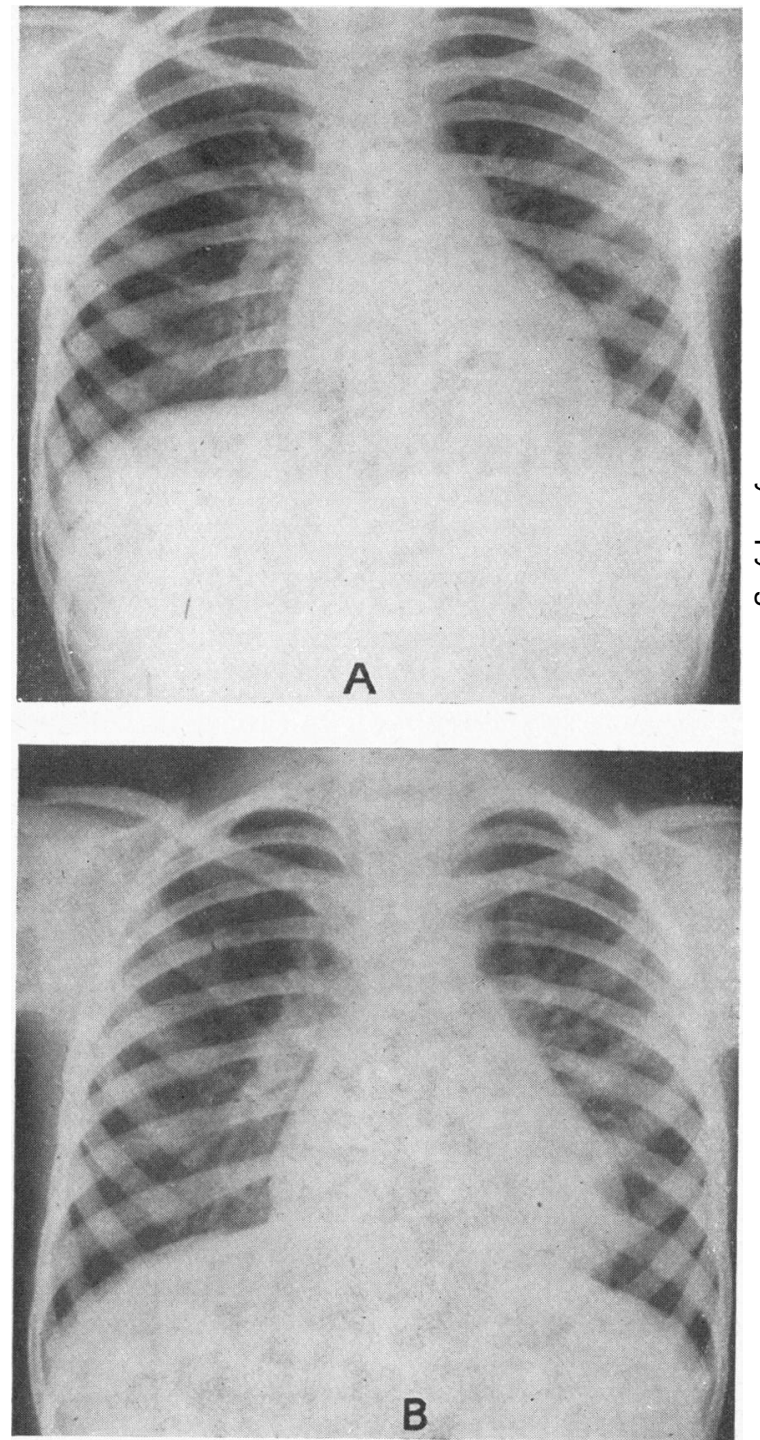

FIG. 3.-Chest radiographs of (A) Donna and (B) Deanna. 
Physical examination and fluoroscopy, radiographs and electrocardiography revealed no abnormality in Donna. Cardiac catheterization was not carried out on this child.

\section{E.C.G. DONNA}
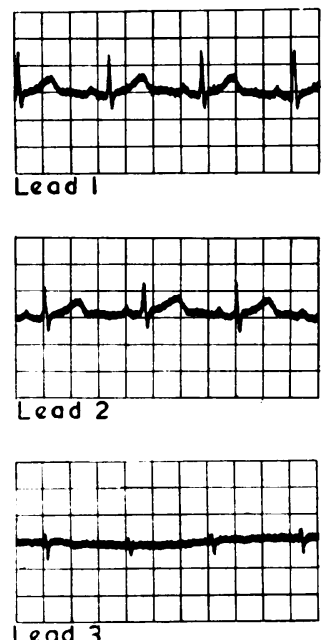

FIG. 4.-Electrocardiograms of the twins.

\section{Discussion}

It was once thought that one of homologous twins never suffered from a malformation not shared by his fellow (McFarland and Meade, 1932). If, therefore, a pair of twins did not show identical abnormalities they were classified as dizygotic. Such interpretations ignored the fact, now accepted, that environment may modify a given hereditary trait. A congenital malformation may result from an error in development, such as an abnormality in the rate of growth or differentiation of the embryo, at some specific time. Muller (1947) points out that the characteristic expression of a given gene complex requires specific environmental conditions.

The possible causes of a congenital malformation are thought to be a genetic defect in the fertilized ovum or a faulty intrauterine environment. To these Dahlberg (1949) suggests that a third factor, ' random variation,' be added, which occurs within the developing embryonic cells.

In certain instances of congenital heart disease, a hereditary trait is apparent. In the present study there is nothing relevant in the family history. Monozygotic twins make a unique contribution to aetiological research as, in respect of their genetic constitution, they are one and the same individual in duplicate. It follows, therefore, that any discordance they may exhibit must be a reflection of differences in their experience subsequent to the twinning division. When one member of a monozygotic pair presents a particular abnormality not shared by his fellow, it is safe to conclude that the cause of the discordance is not genetic.

Of non-hereditary factors resulting in malformation of the embryo, maternal disease is the most obvious. Syphilis and a virus infection during pregnancy have been proved to cause congenital defects in the offspring. It is well known that German measles occurring in the first two months of pregnancy is associated with a high incidence of congenital heart disease. In the present case the mother was in good health throughout her pregnancy.

Twins show a higher incidence of prematurity and stillbirths than singletons (Strandskov and Ondina, 1947). It is a common observation also that congenital abnormalities occur more frequently among multiple pregnancies. In the case of twins the unfavourable factor may act on one of the developing foetuses to produce a malformation or, in some cases, to cause even the death of one twin. The survival of only one member of a monozygotic pair is a well recognized occurrence, and must reflect a difference in uterine environment. The quality of the latter is poorer in women when more than one baby is produced. In the later months of pregnancy crowding and an abnormal intra-uterine position may be injurious to the foetus. However, crowding is minimal during the second month of intra-uterine development, at which time the auricular septum is formed, and it is unlikely to have any bearing upon the present case.

In the monozygotic twins under discussion there was a single placenta with two chorions and two separate circulations. A pressure abnormality in one system, occurring at the time of closure of the auricular septum, might have been the cause of the congenital malformation in only one twin.

An abnormal change in temperature or in $p \mathrm{H}$ within the cells of an embryo in the early stages of development may lead to congenital defects. This random variation might have affected one embryo and not the other, leading to the different expression of the same gene complex in the present monozygotic pair.

\section{Summary}

Auricular septal defect is reported in one of monozygotic twin girls, aged 6 years, her twin being clinically normal. The analysis of zygosity is based upon consideration of the foetal membranes, the blood groups and types, the digital, palmar, and plantar configurations and other physical features. 
The two individuals came to differ in their characterization because of a variation in their experience subsequent to conception, such as differences in their circulation in early pregnancy or some random physico-chemical variation in their embryonic development.

We wish to thank Dr. John D. Keith of the Hospital for Sick Children, Toronto, Dr. Norma Ford Walker of the Department of Zoology, University of Toronto, and Professor F. A. E. Crew, of the Department of Public Health and Social Medicine, University of Edinburgh, for their help and encouragement in the preparation of this paper. We are indebted to Dr. Beatrice M. Corrigan for her translation of the article by Pezzi and Carugati (1924).

\section{REFERENCES}

Cummins, H., and Midlo, C. (1943). 'Finger Prints, Palms and Soles.' Philadelphia.
Dahlberg, G. (1949). Biol. Abstr., 23, 20317.

Dubreuil-Chambardel, L. (1927). Pr. méd., 35, 1157.

Dissmann, E. (1932). Frankfurt. Z. Path., 43, 476.

Giustra, F. X., and Tosti, V. G. (1939). Amer. Heart J., $17,249$.

McClintock, K. (1945). Archives of Disease in Childhood, 20, 47.

McFarland, J., and Meade, T. S. (1932). Amer. J. med. Sci., 184, 66.

Muller, H. J., Little, C. C., and Snyder, L. H. (1947). 'Genetics, Medicine and Man.' New York.

Pezzi, C., and Carugati, L. (1924). Cuore e Circol., 8,361 .

Rabl, R., and Schulz, F. (1940). Virchows Arch., $305,505$.

Smith, K. S. (1929). Archives of Disease in Childhood, 4,330 .

Strandskov, H. H., and Ondina, D. (1947). Amer. J. phys. Anthrop., N.S. 5, 41.

Ullrich, O. (1938). Z. menschl. Vererb. Lehre, 21, 585.

Walker, N. F. (1950). Personal Communication.

Weitz, W. (1936). 'Die Vererbung. innerer Krankheiten,' Stuttgart. 